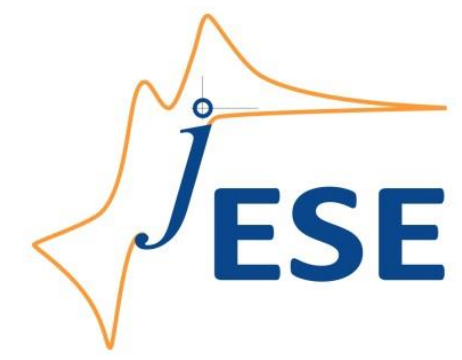

Open Access : : ISSN 1847-9286

www.jESE-online.org

Original scientific paper

\title{
Sucrose fatty esters from underutilized seed oil of Terminalia catappa as potential steel corrosion inhibitor in acidic medium
}

\author{
Adewale Adewuy ${ }^{\varpi}$, Omolade Rahman Bello*, Rotimi A. Oderinde* \\ Department of Chemical Sciences, Faculty of Natural Sciences, Redeemer's University, Ede, Osun \\ state, Nigeria \\ *Industrial Unit, Department of Chemistry, University of Ibadan, Ibadan, Oyo state, Nigeria \\ ${ }^{\square}$ Corresponding author: walexy62@yahoo.com; Phone: +2348035826679
}

Received: June 7, 2016; Revised: November 17, 2016; Accepted: November 18, 2016

\begin{abstract}
Corrosion of metals is a common problem which requires definite attention. In response to this, the oil was extracted from the seed of Terminalia catappa and used to synthesize sucrose fatty esters via simple reaction mechanism which was considered eco-friendly and sustainable. The corrosion inhibition capacity of sucrose fatty esters for mild steel in $1 \mathrm{M} \mathrm{HCl}$ was studied using the weight loss method. It was shown that sucrose fatty ester inhibited corrosion process of mild steel and obeyed Langmuir isotherm. Corrosion rate and inhibition efficiency of sucrose fatty esters were found to reduce with increase of immersion time. The study presented sucrose fatty ester as a promising inhibitor of mild steel corrosion in acidic medium.
\end{abstract}

\section{Keywords}

Adsorption; Corrosion; Adsorption isotherm; Mild steel; Fatty esters

\section{Introduction}

Corrosion is usually taken as breaking down or wearing of materials, mostly metals, through chemical reactions. The most known form of corrosion is rusting, which takes place when iron combines with oxygen and water. Mild steels are known to contain carbon alloyed mainly with copper, chromium, phosphorus, nickel, etc. [1]. Generally, the mild steel shows some resistance to atmospheric corrosion which is attributed to its ability to develop a protective layer. It has already been shown that development of this layer depends on nature, amount and type of alloying elements in the steel and also on exposure, or corrosion initiator conditions [2-5].

Corrosion is the major problem encountered in the industries and areas involving surface equipment and processing facilities. This is seen mainly as leaks in tanks, casings, tubing, pipelines, and other equipment [6,7]. The problem of corrosion affects operations and equipment 
maintenance, which may lead to recurrent partial and even total process shutdown [8]. Use of highly concentrated acids for some industrial unit operations makes the environment corrosive to mild steel, carbon and low-alloy steels. Some of these acids include hydrochloric, hydrofluoric, acetic, or formic acids which are injected into the system during the acidizing stimulation process [9]. This has raised the need or search for a way to control or minimize corrosion. Although several efforts have been made in past, it is still almost impossible to fully prevent corrosion [10]. It is possible, however, to control the process in order to minimize the havoc it brings. Some control of corrosion has been achieved by use of several organic and organometallic compounds [11,12]. Even in very small amounts added to a corrosive environment, such compounds are expected to be effective and efficient in decreasing corrosion rates. In some cases, it has been noticed that these compounds are specific in their actions, being efficient only towards particular metals under specific environmental conditions. In other cases, aside being efficient, they were found toxic to the environment, human and animals $[13,14]$. Inhibition of corrosion is very important phenomenon. Without inhibition, corrosion rate can be extremely high and may go out of control, particularly at increasing temperatures. Due to this, it is important to develop inhibitors that will be effective, environmentally friendly, affordable and of industrial relevance, what would also be important for processes involving acid pickling, industrial cleaning, and acid descaling, where corrosion conditions are usually milder.

Underutilized seed oils are resources which are readily available, cheap, environmentally friendly and affordable. They can be used as starting materials for production of useful products that can serve as corrosion inhibitors [15]. Terminalia catappa oil is an example of underutilized seed oil in Nigeria that can serve this purpose. Presently, the oil has no specific use and is usually being discarded as waste. Finding useful application for this oil will go a long way in making the environment cleaner. As has been reported by Matos et al. [16], the oil contains mainly palmitic (35.96\%), oleic (31.48 \%) and linoleic (28.93\%) fatty acids. Presence of these fatty acids and level of unsaturation represent this oil useful for corrosion inhibitor production.

The present work reports the synthesis of sucrose fatty ester from Terminalia catappa oil and examination of its ability to inhibit corrosion of mild steel in acidic condition. The effect of time and concentration of sucrose fatty acid ester on corrosion rate will also be examined.

\section{Experimental}

\section{Materials}

The seeds of Terminalia catappa were collected from the Botanical garden, University of Ibadan, Oyo state, Nigeria. The seeds were air dried and subsequently ground in a laboratory mill. Dimethyl sulphoxide, hydrochloric acid and sucrose were purchased from Merck, Darmstadt, Germany. Further chemicals and all solvents used in this study were of analytical grade and were purchased from VWR International $\mathrm{GmbH}$, Darmstadt. The dried seeds of Terminalia catappa were later extracted with $n$-hexane for $10 \mathrm{~h}$ using a soxhlet extractor [17].

\section{Synthesis of sucrose fatty ester from Terminalia catappa oil}

For the synthesis of the sucrose fatty ester, $25 \mathrm{~g}$ of sucrose was transferred into a round bottom flask which previously contained dimethyl sulfoxide $(55 \mathrm{~mL})$. The mixture was heated and gently swirled to ensure complete dissolution of the sucrose in the solvent. Terminalia catappa oil $(65 \mathrm{~mL})$ was added to the resulting solution and followed by addition of $\mathrm{K}_{2} \mathrm{CO}_{3}(3 \mathrm{~g})$. The flask with a stopper having thermometer inserted was placed on a heating mantle and allowed reaction to 
proceed for $9 \mathrm{~h}$ at an average temperature of $110^{\circ} \mathrm{C}$ with occasional swirling. A thick brownish product was formed at the end of the reaction. At the end of reaction, the excess dimethyl sulfoxide was removed by distillation and the unreacted sucrose was removed by dissolving it in water. The residue of sucrose fatty ester was filtered, weighed and taken for FTIR analysis.

\section{Corrosion study}

In this study, the weight loss procedure was used for determination of corrosion rates. The mild steel sheets were obtained from the local market in Ibadan, Oyo state, Nigeria. The sheets were degreased in ethanol, dried in acetone, and stored before their use in corrosion studies. The sheets were cut into $4 \times 3 \mathrm{~cm}$ size. The corrosion process was initiated by $\mathrm{HCl}$, while the sucrose fatty ester was used as the inhibitor. The effect of both, initiator and inhibitor, on the corrosion rate was examined by varying the concentration of sucrose fatty ester $(1-3 \mathrm{mg} / \mathrm{L})$ and $\mathrm{HCl}(1-8 \mathrm{M}) .1 \mathrm{M} \mathrm{HCl}$ solution was used as the control solution, while other solutions containing sucrose fatty ester were used as test solutions.

Corrosion study was conducted under total immersion of mild steel sheets in $100 \mathrm{~mL}$ capacity beakers containing $50 \mathrm{~mL}$ test solution at room temperature $(298 \mathrm{~K})$. Mild steel sheets were weighed and separately suspended in different beakers containing solutions. The sheets were retrieved at $1 \mathrm{~h}$ interval progressively for $24 \mathrm{~h}$, washed thoroughly in $20 \% \mathrm{NaOH}$ solution containing $200 \mathrm{~g} / \mathrm{L}$ of zinc dust, rinsed severally in deionized water, cleaned, dried in acetone, and re-weighed. The weight loss (in grammes) was taken as difference in the weight of sheets before and after immersion in test solution [18]. The experiments were carried out in duplicate.

\section{Results and discussion}

\section{Synthesis of sucrose fatty ester from Terminalia catappa oil}

The oil of Terminalia catappa has a light yellowish color and is liquid at room temperature. FTIR spectra of Terminalia catappa seed oil and that of the sucrose fatty ester showed some important absorption bands. For both, the oil and sucrose fatty ester, peaks were noticed at $1747 \mathrm{~cm}^{-1}$ and $1733.33 \mathrm{~cm}^{-1}$, respectively, what were attributed to $C=O$ stretching of ester functional groups. Also, the bands at around $1164.62 \mathrm{~cm}^{-1}$ were ascribed to $\mathrm{C}-\mathrm{O}$ vibrational frequencies in both oil and sucrose fatty ester. Signals that appeared at $2920.04 \mathrm{~cm}^{-1}$ in the oil and at $2931.42 \mathrm{~cm}^{-1}$ in the sucrose fatty esters, were taken to be due to $\mathrm{C}-\mathrm{H}$ stretching of alkanes. Peaks at around $3011 \mathrm{~cm}^{-1}$ were considered to be due to $\mathrm{C}=\mathrm{C}-\mathrm{H}$ vibrational frequency of alkene. Broad and prominent peak at $3384.00 \mathrm{~cm}^{-1}$ was found only in the sucrose fatty ester and attributed to the $\mathrm{O}-\mathrm{H}$ stretching; this peak suggested formation of the sucrose fatty ester.

\section{Corrosion study}

Weight loss during corrosion was calculated as difference in weights at an interval of $1 \mathrm{~h}$. The relationship between weight loss of mild steel in $1 \mathrm{M} \mathrm{HCl}$ at different immersion times is presented in Figure 1. The weight loss of mild steel was found to increase with increase in time. It was observed that mild steel in the blank solution (solution without inhibitor) shows faster loss in weight than in the solution containing inhibitor. This observation indicates that presence of sucrose fatty esters in the solution is able to slow down the process of corrosion. 


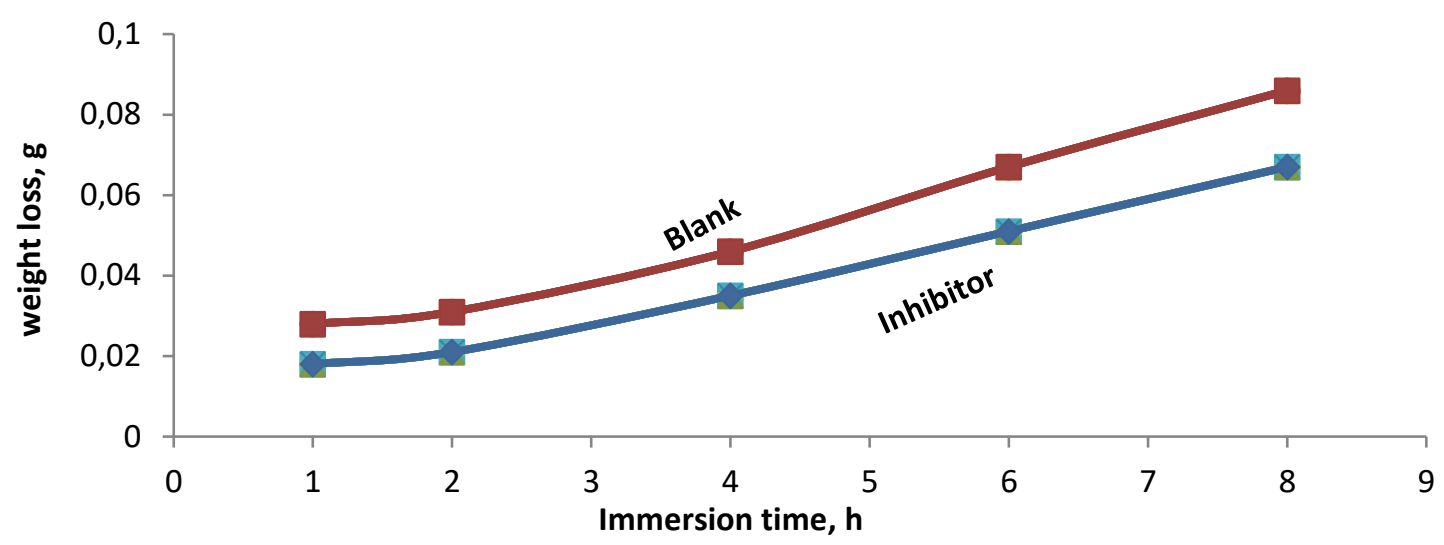

Figure 1. Relationship between weight loss of mild steel and immersion time in $1 \mathrm{M} \mathrm{HCl}$

The observed retardation of corrosion may be due to deposition or adsorption of sucrose fatty esters at the mild steel surface $[18,19]$. Figure 2 also revealed that the process of corrosion of mild steel increases as the strength of the acidic solution increases. This suggests that presence of positively charged hydrogen ions in solution plays a role in attacking the surface of the mild steel for corrosion. Similar observation has been previously reported by Adewuyi et al. [15].

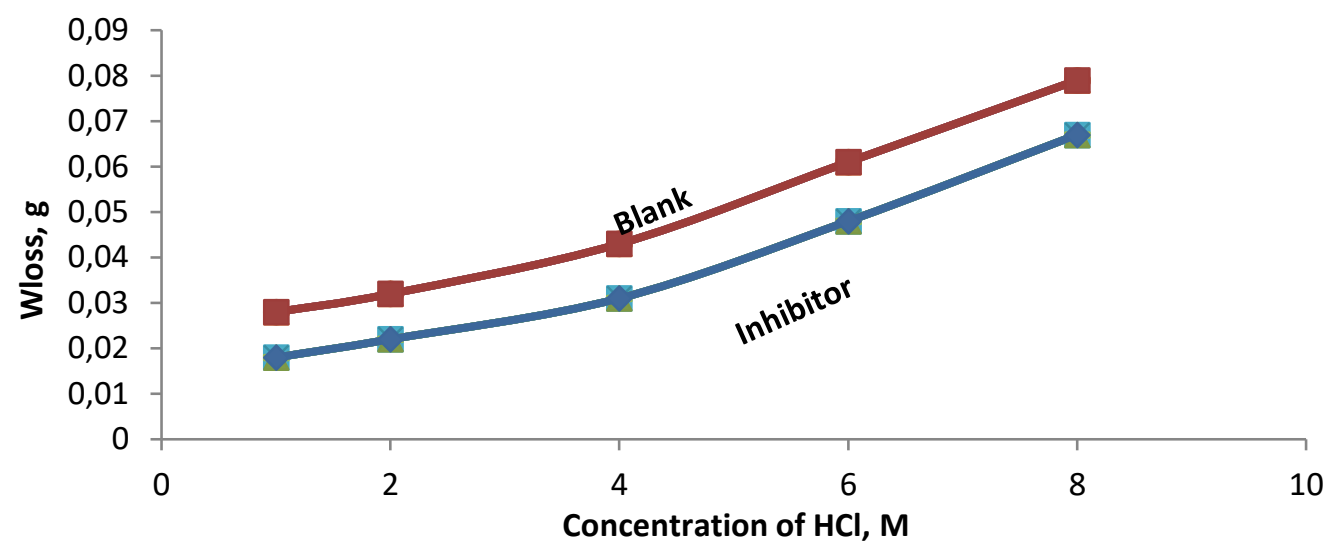

Figure 2. Effect of $\mathrm{HCl}$ concentration on weight loss of mild steel in presence (inhibitor) and absence (blank) of sucrose fatty esters

Corrosion rate was determined using the following expression:

$$
R=\frac{\Delta W}{A t}
$$

In Eq. (1), $R\left(\mathrm{~g} \mathrm{~cm}^{-2} \mathrm{~h}^{-1}\right)$ is the corrosion rate, $\Delta W$ is the average weight loss after immersion, $A$ is the surface area of mild steel and $t$ is the total time $(24 \mathrm{~h})$ of immersion.

Inhibition efficiency $\left(E_{\mathrm{w}} / \%\right)$ for the process was determined as follows:

$$
E_{\mathrm{w}} / \%=\left(R_{0}-\frac{R_{\mathrm{t}}}{R_{0}}\right) \times 100
$$

In Eq. (2), $R_{\mathrm{t}}$ and $R_{0}$ are corrosion rates of mild steel in solutions with and without inhibitor, respectively. The plots of corrosion rates against immersion time are presented in Figure 3 which revealed that with increase of immersion time, the rate of corrosion becomes reduced in both solutions, i.e. blank and solution with inhibitor. 


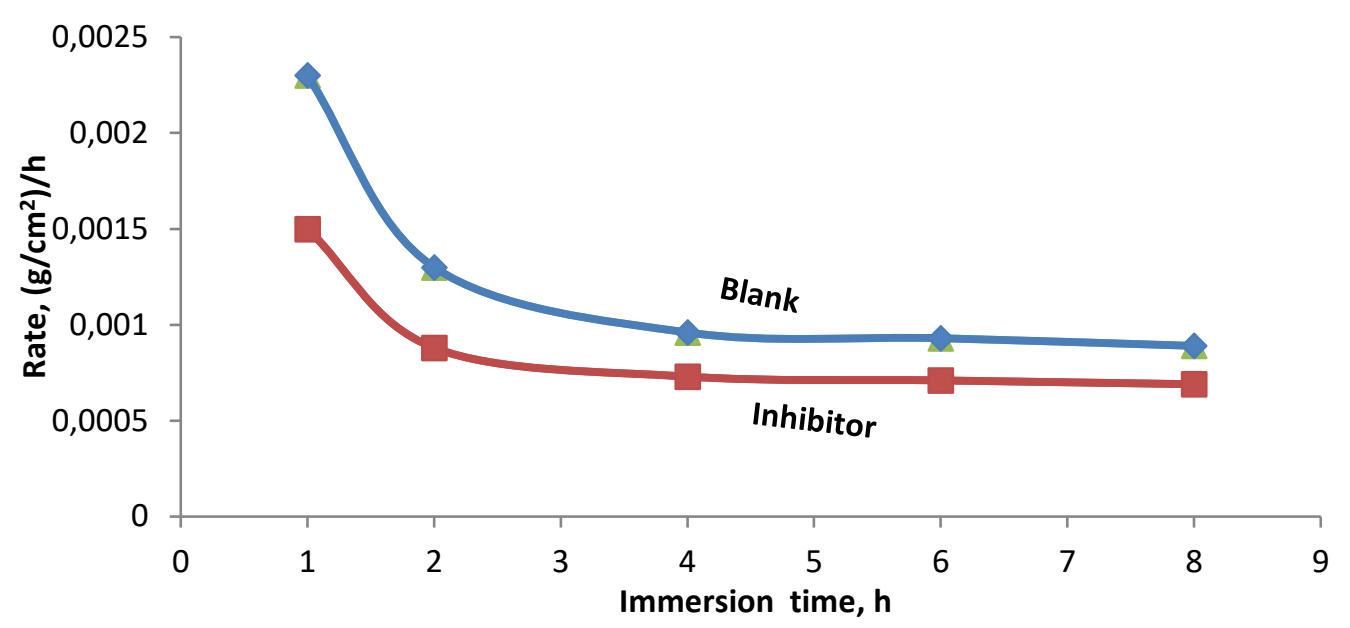

Figure 3. Corrosion rate versus immersion time for mild steel corrosion in presence and absence of sucrose fatty esters

Corrosion is obviously slower in the sucrose fatty ester containing solution, what could be due to the covering of mild steel surface by this inhibitor. For the blank solution, however, this observation may be due to corrosion caused reduction of available surface area during time of immersion. Inhibition efficiency of sucrose fatty esters against mild steel corrosion was also found to reduce with time as shown in Figure 4. It has already been reported that inhibitive mechanism of most organic compounds is based on their adsorption at corroding metal surfaces [20-23]. Therefore, desorption of inhibitor from the surface of mild steel as immersion time increases can possibly explain the results given in Figure 4.

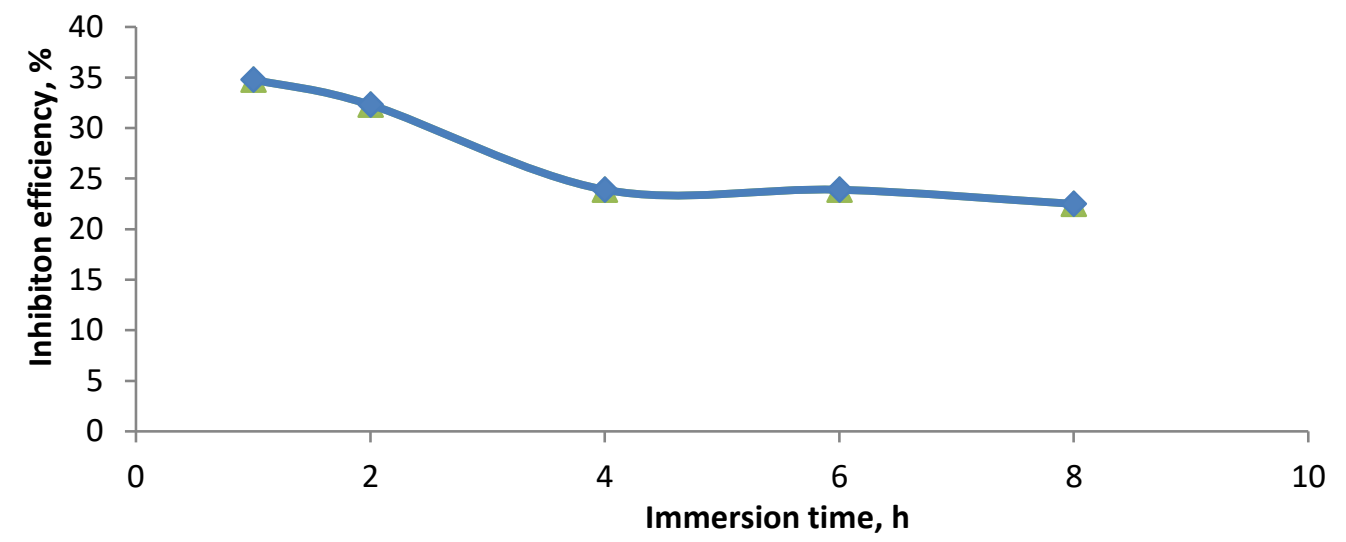

Figure 4. Relationship between inhibition efficiency and immersion time for mild steel corrosion

Table 1. Comparison of the concentration of $\mathrm{HCl}$, weight loss, rate and inhibition efficiency during the corrosion of mild steel

\begin{tabular}{cccc} 
Concentration of SFE, $\mathrm{g} / \mathrm{L}$ & Weight loss, $\mathrm{g}$ & Concentration rate, $\left(\mathrm{g} / \mathrm{cm}^{2}\right) / \mathrm{h}$ & Inhibition efficiency, \% \\
\hline 1.00 & 0.018 & 0.0015 & 34.80 \\
2.00 & 0.022 & 0.0018 & 33.30 \\
4.00 & 0.031 & 0.0026 & 27.80 \\
6.00 & 0.048 & 0.0040 & 20.00 \\
8.00 & 0.067 & 0.0056 & 15.10 \\
\hline
\end{tabular}

Corrosion rate and weight loss were found to increase, while inhibition efficiency was found to decrease as the concentration of $\mathrm{HCl}$ increased. It could be inferred from the results in Table 1 that the corrosion initiator's solution strength was influential in promoting corrosion. It seems that as 
the strength of $\mathrm{HCl}$ increased, there were more species in solution to corrosively attack the metal surface, increasing thus corrosion rate. Reduction of inhibition efficiency may be due to the fact that as concentration of $\mathrm{HCl}$ increased, inhibitor molecules have more contending species at the metal surface and so they are less effective in adsorption/deposition. The effect of concentration of inhibitor on the corrosion rate, inhibitor efficiency and weight loss is presented in Table 2. Data in Table 2 show that inhibition efficiency increased, while corrosion rate is reduced with concentration of sucrose fatty ester. As has already been mentioned above, the observed reduction of corrosion rate may be due to the ability of inhibitor to cover or adsorb at the metal surface.

Table 2. Comparison of the concentration of sucrose fatty ester, weight loss, corrosion rate and inhibition efficiency during corrosion of mild steel

\begin{tabular}{cccc}
\hline Concentration of SFE, $\mathrm{g} / \mathrm{L}$ & Weight loss, $\mathrm{g}$ & Concentration rate, $\left(\mathrm{g} / \mathrm{cm}^{2}\right) / \mathrm{h}$ & Inhibition efficiency, \% \\
\hline 1.00 & 0.0280 & 0.00183 & 20.43 \\
1.50 & 0.0220 & 0.00173 & 24.78 \\
2.00 & 0.0190 & 0.00166 & 27.83 \\
2.50 & 0.0193 & 0.00161 & 30.00 \\
3.00 & 0.0180 & 0.00150 & 34.78 \\
\hline
\end{tabular}

SFE = Sucrose fatty esters

\section{Adsorption isotherm}

Interaction between the metal surface and inhibitor was subjected to adsorption isotherm. The surface coverage $(\theta)$ was derived from the expression:

$$
\theta=\left(R_{0}-\frac{R_{\mathrm{t}}}{R_{0}}\right)
$$

In Eq. (3), $R_{\mathrm{t}}$ and $R_{0}$ are corrosion rates of mild steel with and without inhibitor, respectively. The correlation between $\theta$ and amount of inhibitor in the corroding medium was determined by Langmuir adsorption isotherm which can be expressed as:

$$
\frac{C}{\theta}=\frac{1}{K_{\text {ads }}}+C
$$

In Eq. (4), $C$ is the inhibitor concentration, $\vartheta$ is the surface coverage and $K_{\text {ads }}$ is the equilibrium constant of the inhibitor adsorption process. This model operates on the assumption that adsorption takes place only at specific homogenous sites of metal surface and that adsorption forms a monolayer [22]. As shown in figure 5, the plot of $C / \theta$ versus $C$ gave straight lines $\left(r^{2}=0.968\right)$, suggesting thus the monolayer adsorption of sucrose fatty esters at the surface of the mild steel.

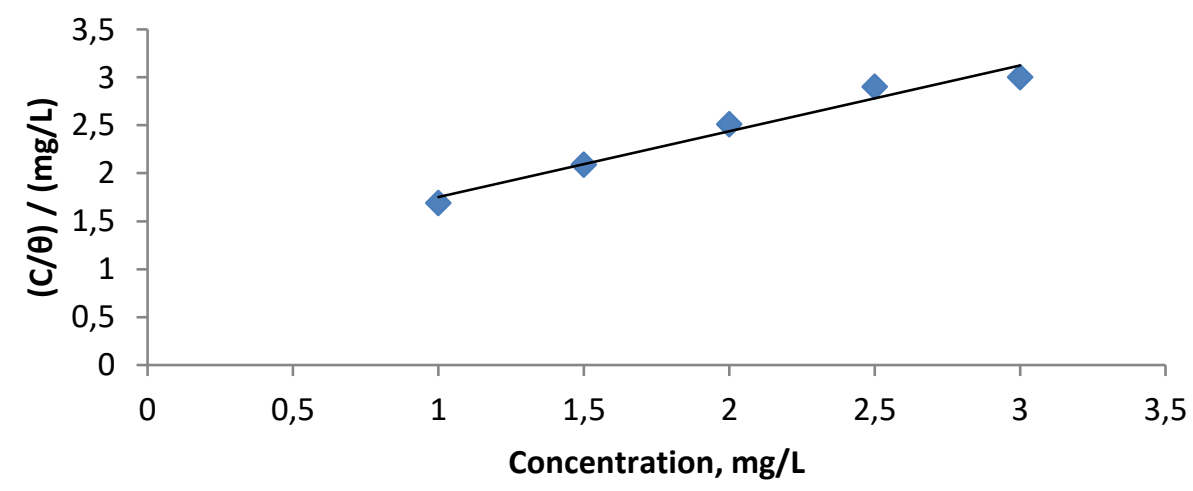

Figure 5. Langmuir adsorption plot for mild steel in $1 \mathrm{M} \mathrm{HCl}$ containing sucrose fatty esters 
The essential characteristic of Langmuir isotherm was calculated as follows:

$$
K=\frac{1}{1+K_{\text {ads }} C}
$$

In Eq. (5), $K_{R}$ is the equilibrium parameter, $K_{\text {ads }}$ is the Langmuir constant and $C$ is the inhibitor concentration. The parameter $K_{R}$ indicates the shape of the isotherm accordingly. It has been reported that when $K_{R}>1$, adsorption is unfavourable; when $K_{R}=1$, adsorption is linear; when $K_{R}=0$, adsorption is irreversible and when $0<K_{R}<1$, adsorption is favourable [24-26]. Here, the calculated $K_{\mathrm{R}}$ values were $<1$, confirming that the adsorption process was favourable and reversible. This also supports the findings that inhibition efficiency is reduced with time which may have been due to the possibility of desorption taking place at the surface of the metal over a period of time.

\section{Conclusion}

Sucrose fatty ester was synthesized from the seed oil of Terminalia catappa and evaluated for corrosion inhibition capacity against mild steel in acidic medium using $\mathrm{HCl}$. The synthesis of the sucrose fatty ester was achieved using simple reaction mechanism which was analyzed using FTIR. The sucrose fatty esters inhibited corrosion of mild steel in $1 \mathrm{M} \mathrm{HCl}$ with inhibition efficiency increasing as the concentration of sucrose fatty esters increased and decreasing with increase in time. Inhibition of corrosion is going via adsorption of sucrose fatty ester on the surface of the metal which obeyed Langmuir isotherm. The study presents sucrose fatty ester from Terminalia catappa as the potential corrosion inhibitor of mild steel.

Acknowledgement: The authors are most grateful to the Department of Chemistry, University of Ibadan, Ibadan, Oyo state and the Department of Chemical Sciences, Redeemer's University, Ede, Osun state for supplying chemicals, equipment and laboratory space for this work.

\section{References}

[1] T. Murata, Weathering steel, in: R.W. Revie (Ed.), Uhlig's Corrosion Handbook, J. Wiley \&Sons, New York, 2000, 569-580

[2] M. Morcillo, B. Chico, I. Díaz, H. Cano, D .de la Fuente, Corros. Sci. 77 (2013) 6-24.

[3] Y. Oshida, E. B. Tuna, O. Aktören, K. Gençay, Int. J. Mol. Sci. 11 (2010) 1580-1678

[4] K. H. Lo, C. H. Shek, J. K. L. Lai, Mat. Sci. Eng. 65 (2009) 39-104

[5] H. Nady, Egypt. J. Petr. (2016) http://dx.doi.org/10.1016/j.ejpe.2016.02.004

[6] M. M. Oman, M. N. Shalaby, Mater. Chem. Phys. 77 (2003) 261-269.

[7] P. C. Okafor, X. Liu, Y. G. Zheng, Corros. Sci. 51 (2009) 761-768.

[8] V. Garcia-Arriaga, J. Alvarez-Ramirez, M. Amaya, E. Sosa, Corros. Sci. 52 (2010) 2268-2279.

[9] M. Finšgar, J. Jackson, Corros. Sci. 86 (2014)17-41

[10] D. Brondel, R. Edwards, A. Hayman, D. Hill, S. Mehta, T. Semerad, Oilfield Rev. 6 (1994) 418.

[11] M. Quraishi, D. Jamal, J. Am. Oil Chem. Soc.77 (2000) 1107-1111.

[12] A. L. D. Q. Baddini, S. P. Cardoso, E. Hollauer, J. A. D. C. P. Gomes, Electrochim. Acta, 53 (2007) 434-446.

[13] W. P. Singh, J. O. Bockris, Corrosion 96 (1996) 24-29

[14] D. I. Horsup, J. C. Clark, B. P. Binks, P. D. I. Fletcher, J. T. Hicks, Corrosion 66 (2010) $036001-$ 036014.

[15] A. Adewuyi, A. Göpfert, T. Wolff, Ind. Crops Prod. 52 (2014) 439- 449 
[16] L. Matos, J. M. Nzikou, A. Kimbonguila, C. B. Ndangui, N. P. G. Pambou-Tobi, A. A. Abena, Th. Silou, J. Scher, S. Desobry, Adv. J. Food Sci. Technol. 1 (2009) 72-77.

[17] A. Adewuyi, A. Göpfert, T. Wolff, Central Eur. J. Chem. 11 (2013) 1368-1380.

[18] A. Adewuyi, A. Göpfert, T. Wolff, Ind. Crops Prod. 52 (2014) 439- 449.

[19] I. B. Obot, N. O. Obi-Egbedi, N. W. Odozi, Corros. Sci. 52 (2010) 923-926.

[20] G. Y. Elewady, I. A. El-Said, A. S. Fouda, Int. J. Electrochem. Sci. 3 (2008) 177-190.

[21] E. E. Ebenso, I. B. Obot, L. C. Murulana, Int. J. Electrochem. Sci. 5 (2010)1574- 1586.

[22] I. B. Obot, N. O. Obi-Egbedi, J. Current. Appl. Phy. 11 (2011) 382- 392.

[23] A. Adewuyi, A. D. Adesina, R. A. Oderinde, Advances in Chemistry, 2014 (2014) 896965, http://dx.doi.org/10.1155/2014/896965.

[24] Y. Ho, Polish J. Environ. Studies 15 (2006) 81-86.

[25] X. H. Li, S. D. Deng, G. N. Mu, H. Fu, F. Z. Yang, Corros. Sci. 50 (2008) 420-430.

[26] A. O. Dada, A. P. Olalekan, A. M. Olatunya, O. Dada, J. Appl. Chem. 3 (2012) 38-45. 